\title{
Gamma-linolenic acid inhibits both tumour cell cycle progression and angiogenesis in the orthotopic C6 glioma model through changes in VEGF, Flt I, ERKI/2, MMP2, cyclin DI, pRb, p53 and p27 protein expression
} Juliano Andreoli Miyake†, Marcel Benadiba ${ }^{\dagger}$ and Alison Colquhoun*

Address: Department of Cell and Developmental Biology, Biomedical Sciences Institute, University of São Paulo, São Paulo, SP, Brazil Email: Juliano Andreoli Miyake - juam@usp.br; Marcel Benadiba - benadiba@usp.br; Alison Colquhoun* - alison@usp.br * Corresponding author †Equal contributors

Published: 17 March 2009

Lipids in Health and Disease 2009, 8:8 doi:10.1186/1476-5IIX-8-8

This article is available from: http://www.lipidworld.com/content/8/I/8

(C) 2009 Miyake et al; licensee BioMed Central Ltd.

This is an Open Access article distributed under the terms of the Creative Commons Attribution License (http://creativecommons.org/licenses/by/2.0), which permits unrestricted use, distribution, and reproduction in any medium, provided the original work is properly cited.
Received: 2 February 2009

Accepted: 17 March 2009

\begin{abstract}
Background: Gamma-linolenic acid is a known inhibitor of tumour cell proliferation and migration in both in vitro and in vivo conditions. The aim of the present study was to determine the mechanisms by which gamma-linolenic acid (GLA) osmotic pump infusion alters glioma cell proliferation, and whether it affects cell cycle control and angiogenesis in the C6 glioma in vivo.
\end{abstract}

Methods: Established C6 rat gliomas were treated for 14 days with $5 \mathrm{mM}$ GLA in CSF or CSF alone. Tumour size was estimated, microvessel density (MVD) counted and protein and mRNA expression measured by immunohistochemistry, western blotting and RT-PCR.

Results: GLA caused a significant decrease in tumour size $(75 \pm 8.8 \%)$ and reduced MVD by $44 \pm$ $5.4 \%$. These changes were associated with reduced expression of vascular endothelial growth factor (VEGF) $(7 \mathrm{I} \pm 16 \%$ ) and the VEGF receptor Flt l (57 $\pm 5.8 \%)$ but not Flkl. Expression of ERKI/2 was also reduced by $27 \pm 7.7 \%$ and $31 \pm 8.7 \%$ respectively. mRNA expression of matrix metalloproteinase- 2 (MMP2) was reduced by $35 \pm 6.8 \%$ and zymography showed MMP2 proteolytic activity was reduced by $32 \pm 8.5 \%$. GLA altered the expression of several proteins involved in cell cycle control. pRb protein expression was decreased $(62 \pm 18 \%)$ while E2FI remained unchanged. Cyclin DI protein expression was increased by $42 \pm 12 \%$ in the presence of GLA. The cyclin dependent kinase inhibitors $\mathrm{p} 21$ and p27 responded differently to GLA, p27 expression was increased $(27 \pm 7.3 \%)$ while $p 21$ remained unchanged. The expression of $p 53$ was increased (44 \pm $16 \%$ ) by GLA. Finally, the BrdU incorporation studies found a significant inhibition (32 $\pm 11 \%)$ of $\mathrm{BrdU}$ incorporation into the tumour in vivo.

Conclusion: Overall the findings reported in the present study lend further support to the potential of GLA as an inhibitor of glioma cell proliferation in vivo and show it has direct effects upon cell cycle control and angiogenesis. These effects involve changes in protein expression of VEGF, FItI, ERKI, ERK2, MMP2, Cyclin DI, pRb, p53 and p27. Combination therapy using drugs with other, complementary targets and GLA could lead to gains in treatment efficacy in this notoriously difficult to treat tumour. 


\section{Background}

Gamma-linolenic acid has been proposed as an antitumour therapy and has proven efficacy in several tumour types $[1,2]$. Studies have used GLA for the treatment of human gliomas although these trials were preliminary in nature [3-5]. Studies in the C6 rat glioma model have shown GLA inhibits cell proliferation and induces apoptosis and similar results have been obtained with human glioma cells in primary culture [6-9]. GLA is known to induce reactive oxygen species generation and cause lipid peroxidation in tumour cells and leads to altered mitochondrial metabolism and ultrastructure, cytochrome c release, caspase activation and apoptosis [10-14]. Both GLA and its metabolic products can alter the gene expression of several proteins and GLA is known to inhibit glioma cell migration [14-16].

One of the major problems of glioma progression is intense angiogenesis which has been related not only to tumour nutrition but also to tumour cell migration along the basement membrane of the growing blood vessels [17]. In gliomas, the best characterized pro-angiogenic factor is vascular endothelial growth factor (VEGF), whose overexpression is correlated with increasingly malignant phenotypes [18]. VEGF and its receptors Flt1 (VEGFR1) and Flk1 (VEGFR2) are important proteins in the angiogenic process and represent a treatment target in many tumours including gliomas. In order for angiogenesis to progress extracellular matrix (ECM) degradation is necessary and the metalloproteinases 2 and 9 (MMP2 and MMP9) are highly expressed in gliomas $[19,20]$. Interestingly, GLA is known to inhibit both endothelial cell proliferation and induce endothelial cell apoptosis. Several studies have reported GLA-induced changes in endothelial cells including altered occludin and VE-cadherin expression and altered barrier properties [21,22]. Polyunsaturated fatty acids have also been reported to influence MMP2 expression in endothelial cells [23]. However the effects of GLA on cell cycle and angiogenesis related proteins in gliomas in vivo has not been explored and is the principal focus of the present study.

The aim of the study was to determine the effects of slow $(0.5 \mu \mathrm{l} / \mathrm{hr})$ osmotic pump infusion of $5 \mathrm{mM}$ GLA on factors related to the angiogenic process and to the control of the cell cycle in the C6 rat glioma model. The mRNA and protein expression were studied of (i) angiogenesis related proteins: vascular endothelial growth factor (VEGF), VEGF receptors Flt1 and Flk1, matrix metalloproteinase 2 (MMP2), matrix metalloproteinase 9 (MMP9), ERK1 and ERK2, and (ii) cell cycle control related proteins: pRb, cyclin D1, E2F1, p16, p21, p27 and p53. Immunohistochemical localization of proteins was performed by light microscopy and semi-quantitative analysis of protein expression was performed for VEGF, Flt1 and Flk1. MMP2 proteolytic activity was determined by zymography in order to determine GLA effects on ECM degradation capacity in vivo. Glial fibrillary acidic protein (GFAP) was immunohistochemically localized in order to determine the tumour area by image analysis. Bromodeoxyuridine (BrdU) incorporation was analysed by immunohistochemical localization of the compound to determine the effects of GLA on S-phase DNA synthesis in vivo.

\section{Methods \\ Cell culture}

C6 rat glioma cells were obtained from the ATCC and stocks were maintained frozen (liquid nitrogen) in Dulbecco's modified Eagle's medium (DMEM) supplemented with $10 \%$ foetal calf serum and $20 \%$ glycerol. Stock cells were grown in DMEM containing 10\% foetal calf serum and antibiotics (penicillin $50 \mathrm{U} / \mathrm{ml}$, streptomycin $50 \mu \mathrm{g} /$ $\mathrm{ml}$ ). Cells in the exponential phase of growth were used, growing in $75 \mathrm{~cm}^{2}$ flasks in a humidified atmosphere of 5\% CO2: $95 \%$ air at $37^{\circ} \mathrm{C}$.

\section{Surgical procedures}

C6 rat glioma cells were grown in Dulbecco's modified Eagle medium (DMEM) containing 10\% foetal calf serum and antibiotics (penicillin/streptomycin). Cells in the exponential phase of growth were used and a suspension prepared in sterile saline at a concentration of $5 \times 10^{5}$ cells per 4-5 $\mu \mathrm{l}$. Adult female Wistar rats of 250-350 g $(\mathrm{n}=34)$ were anaesthetised with an intramuscular injection of ketamine:xylazine, $10 \mathrm{mg}: 1.5 \mathrm{mg} / 100 \mathrm{~g}$ body weight to provide deep anaesthesia and analgesia. The rats were placed on a stereotaxic surgical table, a midline incision was made and a burrhole was drilled $0.48 \mathrm{~mm}$ anterior and 3 mm lateral to bregma. The C6 cell suspension was slowly injected into the striatum using a Hamilton syringe at a depth of $5.4 \mathrm{~mm}$ to the bone surface and the needle left in situ for 3 minutes before its removal. After 14 days Alzet osmotic pumps containing artificial cerebrospinal fluid (CSF) (Alzet) or $5 \mathrm{mM}$ GLA in artificial CSF were surgically implanted and attached to Alzet brain infusion kits. Artificial CSF was chosen as a vehicle solution in order to mimic more closely the composition of the interstitial fluid within the brain. These concentrations were chosen based on previous work and unpublished data from our laboratory [7]. The pump infusion rate was $0.5 \mu \mathrm{l} / \mathrm{hr}$ with a duration of 2 weeks. After a further 14 days the rats were killed by transcardiac perfusion with $4 \%$ formaldehyde in $0.1 \mathrm{M}$ phosphate buffer, $\mathrm{pH} 7.4$ or by anaesthetic overdose for removal of fresh tissues for RT-PCR and western blotting. This procedure was approved by the Ethical Commission for Animal Experimentation of the Biomedical Institute (University of São Paulo) - protocol number $190 / 02$. 


\section{Antibodies}

The antibodies used in this study were: MMP-2 (goat), MMP-2 (mouse), MMP-9 (goat), MMP-9 (mouse), VEGF (mouse), VEGF (rabbit), Flt-1 (rabbit), Flk-1 (rabbit), cd34 (mouse), BrdU (mouse), pRb (rabbit), cyclin D1 (rabbit), E2F1 (rabbit), p16 (mouse), p21 (rabbit), p27 (rabbit), p53 (rabbit), ERK1/ERK2 (rabbit) and GFAP (goat). All of the primary antibodies were purchased from Santa Cruz Biotechnology, USA. Biotinylated Ulex europaeus lectin was from Vector Laboratories, USA. Biotinylated secondary antibodies (anti-goat, anti-mouse and anti-rabbit) used for IHC were produced in donkey (Santa Cruz Biotechnology, USA), and the streptavidin-biotin/ HRP (horseradish peroxidase) was produced by Amersham Biosciences, UK.

\section{Immunohistochemical (IHC) analysis}

The perfused brains were cryoprotected in a solution of $20 \%$ sucrose in $0.1 \mathrm{M}$ potassium phosphate buffer (KPB) overnight. The brain sections were cut on a freezing microtome (Leica SM 2000R) and mounted on gelatinized slides. The sections were dried at $40^{\circ} \mathrm{C}-50^{\circ} \mathrm{C}$ for 2 hours and were maintained at $-20^{\circ} \mathrm{C}$ until analysis. Immunohistochemical analysis followed [14] described briefly here. The sections were incubated at room temperature overnight with the respective primary antibody (MMP-2, MMP-9, Flt-1 and Flk-1, 1:100, VEGF, CD34 and BrdU 1:200 and GFAP, 1:500) diluted in PBST. The negative controls received only PBST. The slides were washed with PBST and incubated with the secondary antibodies (1:500-1:1000 in PBST) for 90 minutes. The slides were washed again with PBST and incubated with streptavidinHRP (1:100-1:200 in PBST) for 60 minutes. The reactions were developed with $0.04 \%$ 3,3'-diaminobenzidine $(\mathrm{DAB})+0.03 \% \mathrm{H}_{2} \mathrm{O}_{2}$. For MMP-2, Flt-1, Flk-1 and GFAP the $\mathrm{DAB}$ reactions were intensified with an $\mathrm{OsO}_{4}$ solution $(0.04 \%)$ for 30 minutes. All slides were counterstained with $0.1 \%$ methyl-green, dehydrated and mounted with Permount $^{\circledR}$ (Fisher Scientific).

\section{mRNA expression analysis by RT-PCR}

Samples were dissected with the aid of a surgical microscope and used for total RNA extraction with Trizol (Life Technologies, USA). The first strand of complementary DNA (cDNA) was generated from $1 \mu \mathrm{g}$ RNA as previously described [24]. PCR amplification cycle: 1 minute at $94^{\circ} \mathrm{C}, 1$ minute at primer-specific temperature and 1 minute at $72^{\circ} \mathrm{C}$. To ensure the exponential phase of amplification, the number of PCR cycles was determined and optimized for each of the proteins. Controls for nonspecific amplification showed no bands on gel (data not shown). Semi-quantitative gene expression data was calculated by the ratio of respective gene/GAPDH density after ethidium bromide staining. GAPDH expression remained unchanged after GLA exposure. Primers used were as follows (sense/antisense):

MMP-2 (500 bp):5'-TGGCAGTGCAATACCTGAAC-3', 5'-CAAGGTCCATAGCTCATCGTC-3';

MMP-9 (531 bp):5'-GAGGAATACCTGTACCGCTATG-3',

5'-CAAACCGAGTTGGAACCAC-3';

VEGF (148 bp):5'-CTGTACCTCCACCATGCCAAG-3',

5'-GGTACTCCTGGAAGATGTCCACC-3';

FLT-1 (453 bp):5'-TGGAAGGAGGCGAGGATTACAGTGAGA-3',

5'GGTAGATTCCAGGTGTGGCATACTCTGGTG-3';

FLK-1(445 bp):5'-GTACTCCAGCGACGAGGCAG-

GACTTTTA-3',

5'-TTTTATCCAGTTTCACAGAGGGCTCCATTG-3';

GAPDH (306 bp):5'-GTCGGTGTGAACGGATTTG-3',

5'-ACAAACATGGGGGCATCAG-3';

ERK1 (188 bp) 5'-CCTGCTGGACCGGATGTTA-3'

5'-GTCTCTTGGAAGATCAGCTC-3'

pRb (549 bp): 5'-TCTACСTCССTTTCССТGTTT-3',

5'-AGTCATTTTTGTGGGTGTTGG-3';

p16 (180 bp): 5'-TCTGCAGATAGACTAGCCA-3',

5'-CTCGCAGTTCGAATCTGCA-3';

p21 (200 bp): 5'-TCCGATCCTGGTGATGTCC-3',

5'-CGAACACGCTCCCAGACGT-3';

p27 (325 bp): 5'-GCAGCTTGCCCGAGTTCTAC-3',

5'-TTCTTGGGCGTCTGCTCCAC-3';

p53 (271 bp): 5'-GTGGCCTCTGTCATCTTCCG-3',

5'-CCGTCACCATCAGAGCAACG-3';

E2F1 (143 bp): 5'-ACGCTATGAAACCTCACTAAA-3', 


\section{5'-AGGACATTGGTGATGTCATA-3';}

Cyclin D1 (435 bp): 5'-TGTTCGTGGCCTCTAAGATGA-3',

\section{5'-GCTTGACTCCAGAAGGGCTT-3'.}

\section{Western blotting}

20- $\mu$ g sample proteins were electrophoresed through 7.5\% SDS-PAGE and transferred to nitrocellulose membranes (Hybond ECL membrane, Amersham Pharmacia Biotech). Immunoblotting followed standard methods [9] and fluorescent bands (Alexa-488 label) were visualized in an image system (Molecular Dynamics Typhoon 8600 Variable Mode Imager). The secondary antibodies conjugated with Alexa-488 (anti-goat, anti-mouse and anti-rabbit) used were produced in donkey (Invitrogen Molecular Probes).

\section{BrdU incorporation}

DNA synthesis was determined in vivo by administration of $100 \mathrm{mg} / \mathrm{kg}$ BrdU intraperitoneally 90 minutes before transcardiac perfusion of CSF or GLA + CSF treated rats. Immunohistochemical detection of cells containing BrdU was performed on cryosections as described above. The method used followed doses used in mouse studies [25].

\section{Zymography}

The activity of MMP2 and MMP9 was detected using zymography on a 10\% SDS-PAGE gel containing $1 \mathrm{mg} / \mathrm{ml}$ gelatin. The proteolytic activity was identified as clear bands on a blue background after Coomassie blue staining of the gel after protein separation by electrophoresis and incubation for 20 hrs following the method of [26]. The intensity of the bands was determined by densitometry and the activity was attributed to MMPs as it was readily inhibited by $5 \mathrm{mM}$ EDTA solution during development.

\section{Gas Chromatography-Mass Spectrometry Analysis}

Lipids were extracted and fatty acid methyl esters were formed by the sulphuric acid/anhydrous methanol method $[27,28]$. The fatty acid methyl esters were separated on a DB-23 column [(50\% cyanopropyl)methyl polysiloxane, $0.25 \mu \mathrm{m}$ film thickness, $0.250 \mathrm{~mm} \times 60 \mathrm{~m}$ ], in a Shimadzu GCMS model QP5050 as described in [14]. Individual fatty acid methyl esters were identified by comparison with authentic standard retention times and mass spectra.

\section{Experimental Analyses}

Immunohistochemistry images were captured and analysed using a CCD camera, an Olympus Optiphot microscope and Image ProPlus software. All labelling above background intensity was selected and a mask created for immunolabelling area calculations on calibrated images.
Values were expressed in $\mu \mathrm{m}^{2} \pm$ SEM and are the mean of 6-10 random areas within each tumour section for each experimental animal, totalling 664 areas analysed for this experiment.

The microvessel density was calculated by counting 5 random high power fields ( $\times 40$ objective) in each tumour section for each experimental animal, totalling 145 areas analysed for this experiment. Vessels of less than $14 \mu \mathrm{m}$ were considered as microvessels, following criteria from [29].

Tumour area was estimated by two parameters the first being area analysis after image capture of GFAP labelled tumour sections. The second method was by calculating the rostrocaudal extension of the tumour (length) from the number of cryosections obtained for immunohistochemical analysis multiplied by section thickness. Image analysis was performed using Sigma Scan and Image Pro Plus software.

The semi-quantitative analysis of RT-PCR products and quantitative analysis of Western blots was performed using a Molecular Dynamics Typhoon 8600 Variable Mode Imager and ImageQuant. All data are presented as the mean \pm SEM. Statistical differences were determined by one-way ANOVA with post-hoc Tukey's test and $\mathrm{p}<0.05$ was considered significant.

\section{Results}

The infusion of $5 \mathrm{mM}$ GLA in CSF caused a significant decrease in C6 tumour growth in comparison with CSF alone in vivo (Figure 1A), as previously reported at lower concentrations [7]. The average tumour area was reduced by $75 \pm 8.8 \%$ while the tumour length (rostrocaudal extension) was reduced by $38 \pm 9.7 \%$. Tumour fatty acid composition was also altered by GLA treatment with significant increases in 18:3, n-6 and 22:5, n- 6 content (Figure 1E).

After confirmation of the efficacy of treatment the expression of angiogenesis related proteins was examined by mRNA and/or protein expression analysis. The mRNA and protein expression of VEGF and its receptors Flt 1 and Flk1 were compared in control CSF and $5 \mathrm{mM}$ GLA treated animals. In Figure 1B, 1D the mRNA expression of VEGF was reduced by $38 \pm 5.8 \%$ in the presence of $5 \mathrm{mM}$ GLA while the protein expression was reduced by $71 \pm 16 \%$. The mRNA expression of Flt 1 was reduced by $77 \pm 16 \%$ in the presence of $5 \mathrm{mM}$ GLA while the protein expression was reduced by $57 \pm 5.8 \%$ (Figure 1F, 1G). While GLA increased the mRNA expression of Flk1 by $39 \pm 12 \%$ its protein expression was unchanged in the GLA treated tumour (data not shown). 

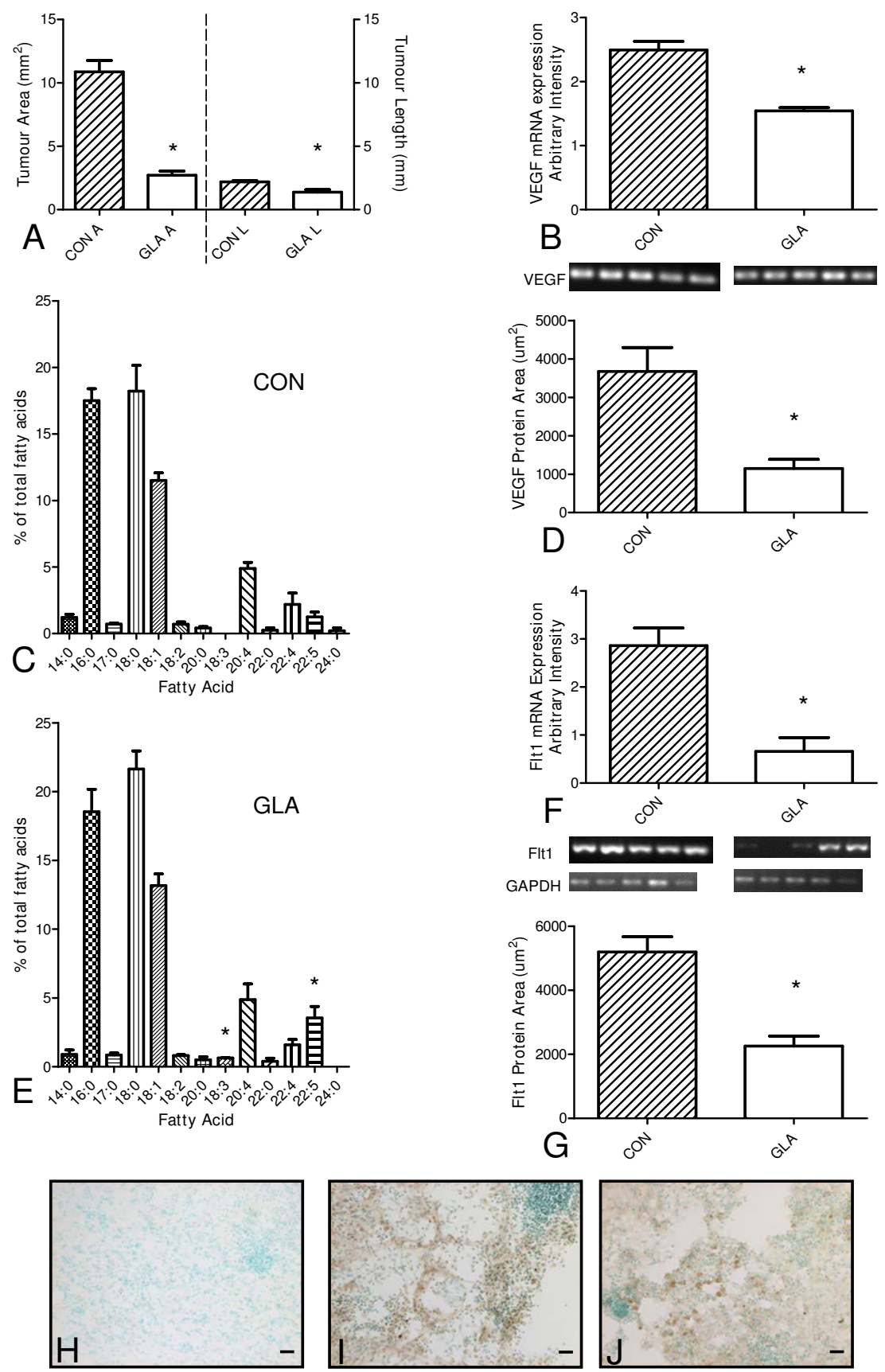

\section{Figure I}

Effect of I 4-day osmotic pump infusion of $5 \mathrm{mM}$ gamma-linolenic acid (GLA) or control cerebrospinal fluid (CON = CSF) on $\mathbf{C 6}$ glioma development in vivo. (A) Tumour size estimated by glial fibrillary acidic protein labeling and image analysis with ImageProPlus. Average tumour area $\left(\mathrm{mm}^{2}\right)$ and length $=$ rostral-caudal extension $(\mathrm{mm})$ were plotted for CON (control CSF) and GLA $(5 \mathrm{mM} \mathrm{GLA}+\mathrm{CSF})(\mathrm{n}=12)$, statistical significance, $*=p<0.000 \mathrm{l}$. Left side of graph presents area (CON A and GLA A) while right side of graph presents length (CON L and GLA L). (B and F) mRNA expression of VEGF and Flt- $\mathrm{I}$ in CON and GLA-treated tumours, with GAPDH as an internal control $(\mathrm{n}=10)$, statistical significance, $*=p<0.00 \mathrm{I}$. (D and $G$ ) Immunohistochemical labeling for VEGF and Flt-I CON and GLA-treated tumours, semi-quantitative analysis with ImageProPlus. $(n=9)$, statistical significance, $*=p<0.01$ ( $C$ and $E$ ) Fatty acid composition by gas chromatography-mass spectrometry of CON $(C)$ and GLA $(E)$ treated tumours $(n=I I)$, statistical significance, $*=p<0.000 \mathrm{I}$. $(\mathrm{H}-\mathrm{J})$ Representative images of control $(H)$, VEGF $(I)$ and Flt-I $(J)$ immunohistochemical labeling $(n=9)$. 
GLA infusion was associated with a decrease in MMP2 (35 $\pm 6.8 \%$ ) mRNA expression (Figure 2A). MMP9 mRNA was not expressed by the tumour and this was confirmed by negative staining with MMP9 antibody on cryosections and lack of activity in zymograms (data not shown). Due to the heterogeneous distribution of MMP2 in the tumour tissue immunohistochemical quantification was not possible. Zymography confirmed a significant decrease (32 \pm $8.5 \%$ ) in proteolytic activity of MMP2 in the presence of GLA (Figure 2B). The presence of $5 \mathrm{mM}$ GLA caused a significant decrease in both ERK1 $(27 \pm 7.7 \%)$ and ERK2 (31 $\pm 8.7 \%$ ) protein expression (Figure $2 \mathrm{C}, 2 \mathrm{E}$ ) and mRNA expression (data not shown).

In the knowledge that $5 \mathrm{mM}$ GLA caused significant changes in mRNA expression and protein expression of important factors involved in the angiogenic process we further investigated these effects by measuring the microvessel density of treated and control tumours. The microvessel density of the GLA treated tumour was reduced by $44 \pm 5.4 \%$ versus the control tumour (Figure $2 \mathrm{G}$ ).

GLA was found to alter the expression of several proteins involved in cell cycle control (Figure 3). pRb protein expression was decreased $(62 \pm 18 \%)$ while E2F1 remained unchanged (Figure $3 \mathrm{~A}, 3 \mathrm{~B}$ ). Cyclin D1 protein expression was increased by $42 \pm 12 \%$ in the presence of GLA (Figure 3C). The cyclin dependent kinase inhibitors p21 and p27 responded differently to GLA, p27 expression was increased $(27 \pm 7.3 \%)$ while p21 remained unchanged (Figure 3D, 3E). C6 glioma cells did not express the cyclin-dependent kinase inhibitor p16 (data not shown) as previously reported [30]. The expression of p53 was increased $(44 \pm 16 \%)$ by GLA (Figure 3F). Finally, the BrdU incorporation studies found a significant inhibition $(32 \pm 11 \%)$ of BrdU incorporation into the tumour in vivo (Figure 3G).

\section{Discussion}

Previous studies have shown that GLA is an effective inhibitor of glioma cell proliferation both in vitro and in vivo $[6,7,14]$. During in vivo studies infusion of $2 \mathrm{mM}$ GLA at $1 \mu \mathrm{l} / \mathrm{hr}$ for 7 days caused a marked inhibition ( $50 \%)$ of tumour growth accompanied by apoptosis [7]. This finding stimulated our hypothesis that a longer period of infusion at higher concentrations may be more effective. The present study infused $5 \mathrm{mM}$ GLA at $0.5 \mu \mathrm{l} / \mathrm{hr}$ for 14 days and the tumour area was significantly reduced $(75 \pm$ $8.8 \%$ ) in comparison with the CSF treated tumours and confirmed the efficacy of this treatment method in gliomas.

The presence of GLA caused inhibition of mRNA expression of VEGF, Flt1, ERK1/2 and MMP2 but not Flk1. Immunohistochemical quantification confirmed the decrease in VEGF and Flt1 protein expression and found a lack of change in Flk1 protein content. ERK1 and ERK2 mRNA and protein expression was significantly decreased. The importance of VEGF and its receptors Flt 1 and Flk1, along with ERK1/2 and MMP2 in glioma angiogenesis and the inhibitory effects of GLA on these proteins' expression suggested the possibility that angiogenesis could be modified in the GLA-treated tumours. After counting microvessel density (MVD) in both groups it was apparent that GLA had an inhibitory effect on vessel number causing a $44 \pm 5.4 \%$ reduction in MVD. These interactions are summarized in the scheme presented in Figure $3 \mathrm{H}$. This in itself could be an important mechanism of tumour growth inhibition by reducing tumour nutrition and by reducing the potential for migration along blood vessels whose number is reduced by treatment.

While the role of Flk1 in endothelial proliferation is well known, the role of Flt 1 is less well defined. Flt1 can be found at both the cell membrane and in soluble form in the extracellular matrix (ECM) where it is believed to influence the angiogenic process [31,32]. It has been suggested that Flt 1 may protect VEGF from proteolytic degradation by binding to it in the ECM [33]. The decrease in Flt1 expression seen in the presence of GLA may reduce the degree of protection of VEGF from degradation in the ECM thereby compounding the effect of decreased VEGF expression. An autocrine loop has been described in neuroblastoma involving VEGF, Flt1 and ERK1/2 [34] and our current data suggest that GLA may interfere with this loop leading to inhibition of tumour cell proliferation and survival in C6 cells in vivo.

From the present study it may be suggested that the marked reduction in Flt1 and VEGF expression caused by GLA treatment could cause a reduction in angiogenesis as seen by reduced MVD most likely through reduced endothelial cell proliferation, although this was not quantified directly. The decrease in ERK1 and ERK2 expression may be involved in the decrease in VEGF and Flt 1 expression in the GLA treated tumours. In addition, the decrease in ERK1 and ERK2 expression could be directly linked to decreased MMP2 expression and proteolytic activity in the GLA treated tumours. Recent studies have shown that ERK-specific inhibitors cause a decrease in the expression of MMP2 in breast cancer brain metastases [35]. In addition, previous studies have shown that the n-3 PUFA's 20:5 and 22:6 cause decreased pERK concomitant with decreased VEGF expression in HT29 colon cancer cells. These n-3 PUFA's also caused a reduction in HT29 tumour volume in vivo and the tumour microvessel density was reduced [36]. It is possible that GLA may affect C6 glioma cells in a similar manner although this remains to be confirmed. 

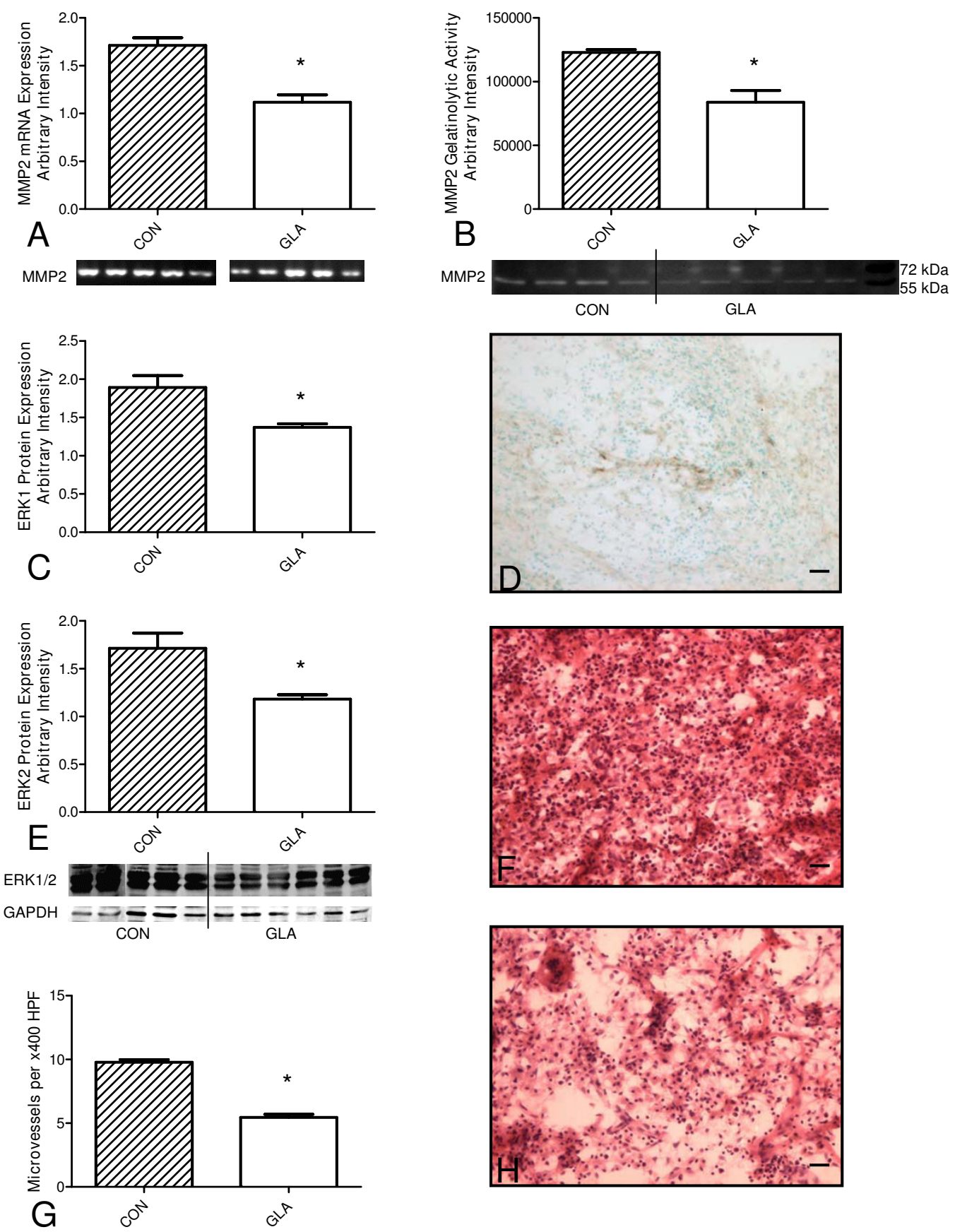

Figure 2

Effect of I4-day osmotic pump infusion of $5 \mathrm{mM}$ gamma-linolenic acid (GLA) or control cerebrospinal fluid (CON = CSF) on protein expression and angiogenesis in the $\mathbf{C 6}$ glioma in vivo. (A) mRNA expression of MMP2 in CON and GLA-treated tumours, with GAPDH as an internal control $(n=10)$, statistical significance, $*=p<0.001$. (B) Zymographic detection of MMP2 proteolytic activity in CON and GLA-treated tumours $(n=9)$, statistical significance, $*=p<0.004$. Lanes I-4 CON, 5-9 GLA. (C and E) Western blot of ERKI and ERK2 protein expression, with GAPDH as an internal control $(n=I I)$, statistical significance, $*=p<0.006$. Lanes I-5 CON, 6-II GLA. (D) Representative images of MMP2 immunohistochemical labeling $(n=9)$. $(F$ and $H)$ Haematoxylin and eosin stained sections of CON $(F)$ and GLA $(H)$ treated tumours. Note large number of blood vessels and tumour cells in the CON tumour in comparison with the GLA treated tumour. (G) Number of microvessels in CON and GLA-treated tumours $(n=9)$. Statistical significance, $*=p<0.00 \mathrm{I}$. 

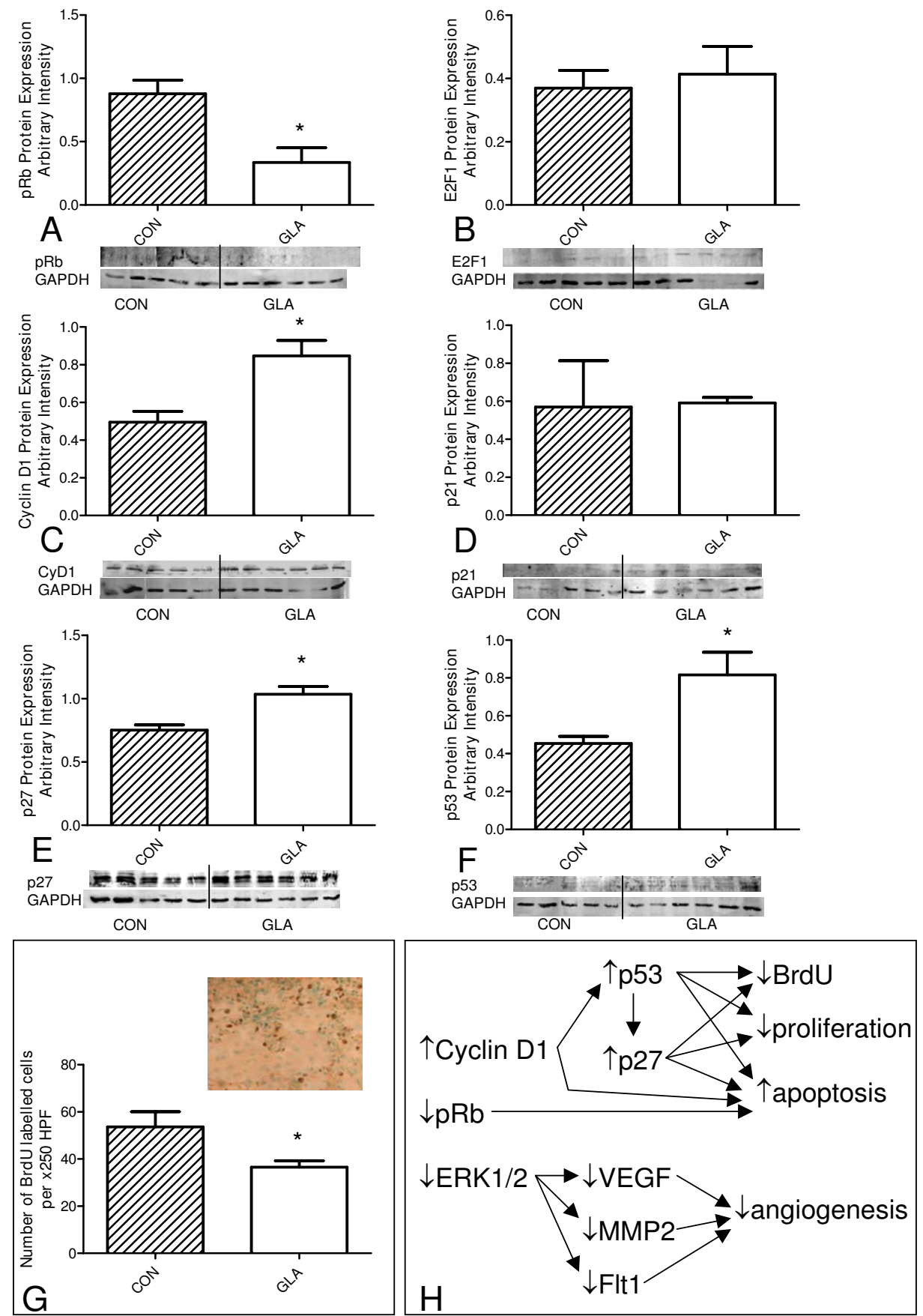

Figure 3

Effect of I4-day osmotic pump infusion of $5 \mathrm{mM}$ gamma-linolenic acid (GLA) or control cerebrospinal fluid $(\mathbf{C O N}=\mathbf{C S F})$ on cell cycle control in the $\mathbf{C 6}$ glioma in vivo. (A) Western blot of pRb protein expression, statistical significance, $*=p<0.009$. (B) Western blot of E2FI protein expression. (C) Western blot of cyclin DI protein expression, statistical significance, $*=p<0.008$. (D) Western blot of p2l protein expression. (E) Western blot of p27 protein expression, statistical significance, $*=p<0.005$. (F) Western blot of $p 53$ protein expression, statistical significance, $*=p<0.026$. For all Western blots GAPDH was used as an internal control and is presented below the protein bands of interest in $A-F,(n=I I)$, Lanes I-5 CON, 6-II GLA. (G) Bromodeoxyuridine incorporation in vivo, representative image of labelled cells ( $\mathrm{n}=9$ ), statistical significance, $*=p<0.015$. (H) Schematic presentation of changes found in GLA-treated tumours in comparison with control tumours and possible interactions among proteins based on current literature. 
Together with the changes in angiogenesis seen in GLA treated tumours several important changes were found in cell cycle control. The combination of decreased $\mathrm{pRb}$ in the absence of functional p16 may cause the cell to lose adequate control over the pRb pathway which is reinforced by the increase in cyclin D1 expression. Increased p53 expression together with these changes in pRb and cyclin D1 can significantly increase cell apoptosis [37-39]. E2F1 expression remained unchanged, in contrast to previous findings in vitro, demonstrating the potential importance of the orthotopic tumour microenvironment on cell responses to GLA treatment [9]. The increase in p53 seen in the GLA treated tumour did not lead to altered p21 expression which could explain why $\mathrm{pRb}$ was not increased in this model. Instead GLA caused a significant increase in another cyclin-dependent kinase inhibitor, p27, causing a G1/S transition block and subsequently reducing S-phase. This was confirmed by a reduction in Sphase BrdU incorporation and was similar to the findings reported for C6 glioma cells in vitro where $150 \mu \mathrm{M}$ GLA caused a $49 \%$ decrease in S-phase [8]. These interactions are summarized in the scheme presented in Figure $3 \mathrm{H}$.

\section{Conclusion}

Overall the findings reported in the present study lend further support to the potential of GLA as an inhibitor of glioma cell proliferation in vivo and show it has direct effects upon cell cycle control and angiogenesis in this orthotopic model. Proteins related to angiogenesis which were altered by GLA treatment included VEGF, Flt1, ERK1, ERK2 and MMP2, while those related to cell cycle control altered by GLA treatment included Cyclin D1, pRb, p53 and p27. Combination therapy using drugs with other, complementary targets and GLA could lead to gains in treatment efficacy in this notoriously difficult to treat tumour.

\section{Competing interests}

The authors declare that they have no competing interests.

\section{Authors' contributions}

JAM and MB made an equal contribution to the experimental work reported in this manuscript and as such should be considered as joint first authors. AC participated in the design, execution and analysis of the study and performed the surgical procedures.

\section{Acknowledgements}

This research was funded by the Brazilian research foundations FAPESP, CNPq and CAPES.

\section{References}

I. Begin ME, Ells G, Das UN, Horrobin DF: Differential killing of human carcinoma cells supplemented with $n-3$ and n-6 polyunsaturated fatty acids. J Natl Cancer Inst 1986, 77: 1053-62.
2. Colquhoun A, Curi R: Effects of saturated and polyunsaturated fatty acids on human tumour cell proliferation. Gen Pharmacol 1998, 30(2): 191-194.

3. Das UN, Prasad VV, Reddy DR: Local application of gamma-linolenic acid in the treatment of human gliomas. Cancer Lett 1995, 94: 147-55.

4. Bakshi A, Mukherjee D, Bakshi A, Banerji AK, Das UN: Gammalinolenic acid therapy of human gliomas. Nutrition 2003, 19:305-9.

5. Das UN: Gamma-linolenic acid therapy of human glioma-a review of in vitro, in vivo, and clinical studies. Med Sci Monit 2007, I3(7):RA||9-|3|.

6. Leaver HA, Bell HS, Rizzo MT, Ironside JW, Gregor A, Wharton SB, Whittle IR: Antitumour and pro-apoptotic actions of highly unsaturated fatty acids in glioma. Prostaglandins Leukot Essent Fatty Acids 2002, 66: 19-29.

7. Leaver HA, Wharton SB, Bell HS, Leaver-Yap IM, Whittle IR: Highly unsaturated fatty acid induced tumour regression in glioma pharmacodynamics and bioavailability of gamma linolenic acid in an implantation glioma model: effects on tumour biomass, apoptosis and neuronal tissue histology. Prostaglandins Leukot Essent Fatty Acids 2002, 67:283-92.

8. Leaver HA, Williams JR, Smith C, Whittle IR: Intracellular oxidation by human glioma cell populations: effect of arachidonic acid. Prostaglandins Leukot Essent Fatty Acids 2004, 70:449-53.

9. Benadiba M, Miyake JA, Colquhoun A: Gamma-linolenic acid alters Ku80, E2FI and Bax Expression and induces micronucleus formation in C6 glioma cells in vitro. IUBMB Life 2009, 6I:244-5I.

10. Leaver HA, Williams JR, Ironside JW, Miller EP, Gregor A, Su BH, Prescott RJ, Whittle IR: Dynamics of reactive oxygen intermediate production in human glioma: $n-6$. Essential fatty acid effects. Eur J Clin Invest 1999, 29:220-31.

II. Colquhoun A, Schumacher RI: Gamma-linolenic acid and eicosapentaenoic acid induce modifications in mitochondrial metabolism, reactive oxygen species generation, lipid peroxidation and apoptosis in Walker 256 rat carcinosarcoma cells. Biochim Biophys Acta 200I, 1533:207-19.

12. Colquhoun A, Schumacher RI: Modifications in mitochondrial metabolism and ultrastructure and their relationship to tumour growth inhibition by gamma-linolenic acid. Mol Cell Biochem 2001, 218:13-20.

13. Colquhoun A: Gamma-linolenic acid alters the composition of mitochondrial membrane subfractions, decreases outer mitochondrial membrane binding of hexokinase and alters carnitine palmitoyltransferase I properties in the Walker 256 rat tumour. Biochim Biophys Acta 2002, I583:74-84.

14. Ramos KL, Colquhoun A: Protective role of glucose-6-phosphate dehydrogenase activity in the metabolic response of C6 rat glioma cells to polyunsaturated fatty acid exposure. Glia 2003, 43: 149-66.

15. Jiang WG, Bryce RP, Horrobin DF, Mansel RE: Gamma-linolenic acid blocks cell cycle progression by regulating phosphorylation of p27kip I and p57kip2 and their interactions with other cycle regulators in cancer cells. Int J Oncol 1998, 13:6 II-7.

16. Yu Q, Shan Z, Ni K, Qian SY: LC/ESR/MS study of spin trapped carbon-centred radicals formed from in vitro lipoxygenasecatalysed peroxidation of gamma-linolenic acid. Free Radic Res 2008, 42:442-55.

17. Farin A, Suzuki SO, Weiker M, Goldman JE, Bruce JN, Canoll P: Transplanted glioma cells migrate and proliferate on host brain vasculature: a dynamic analysis. Glia 2006, 53:799-808.

18. Kaur B, Tan C, Brat DJ, Post DE, Van Meir EG: Genetic and hypoxic regulation of angiogenesis in gliomas. I Neurooncol 2004, 70:229-43.

19. Lakka SS, Gondi CS, Rao JS: Proteases and glioma angiogenesis. Brain Pathol 2005, I 5:327-4I.

20. Takahashi M, Fukami S, Iwata N, Inoue K, Itohara S, Itoh H, Haraoka J, Saido T: In vivo glioma growth requires host-derived matrix metalloproteinase 2 for maintenance of angioarchitecture. Pharmacol Res 2002, 46:155-63.

21. Jiang WG, Bryce RP, Horrobin DF, Mansel RE: Regulation of tight junction permeability and occludin expression by polyunsaturated fatty acids. Biochem Biophys Res Commun 1998, 244:4I 4-20.

22. Cai J, Jiang WG, Mansel RE: Inhibition of the expression of VEcadherin/catenin complex by gamma linolênico acid in 
human vascular endothelial cells, and its impact on angiogenesis. Biochem Biophys Res Commun 1999, 258: I 13-8.

23. Tsuzuki T, Shibata A, Kawakami Y, Nakagawa K, Miyazawa T: Conjugated eicosapentaenoic acid inhibits vascular endothelial growth factor-induced angiogenesis by suppressing the migration of human umbilical vein endothelial cells. J Nutr 2007, 137:64I-6.

24. Ribeiro G, Benadiba M, Colquhoun A, Silva DO: Diruthenium (II, III), complexes of ibuprofen, aspirin, naproxen and indomethacin non-steroidal anti-inflammatory drugs: Synthesis, characterization and their effects on tumor-cell proliferation. Polyhedron 2008, 27: I|3|-|| 37.

25. Guo P, Hu B, Gu W, Xu L, Wang D, Huang HJ, Cavenee WK, Cheng $S Y$ : Platelet-derived growth factor- $B$ enhances glioma angiogenesis by stimulating vascular endothelial growth factor expression in tumor endothelia and by promoting pericyte recruitment. Am J Pathol 2003, 162:1083-93.

26. Hawkes SP, Li H, Taniguchi GT: Methods in Molecular Biology I5 I. Matrix Metalloproteinase Protocols 2001:399-4I0.

27. Folch J, Lees M, Sloane-Stanley GH: A simple method for the isolation and purification of total lipids from animal tissues. J Biol Chem 1957, 226:497-509.

28. Kitson G, Larsen BS, McEwen CN, editors: Gas chromatography and mass spectrometry: a practical guide. New York: Academic Press; 1996:337.

29. Pistolesi S, Boldrini L, Gisfredi S, De leso K, Camacci T, Caniglia M, Lupi G, Leocata P, Basolo F, Pingitore R, Parenti G, Fontanini G: Angiogenesis in intracranial meningiomas: immunohistochemical and molecular study. Neuropathol Appl Neurobiol 2004, 30:1 1 8-25.

30. Strauss BE, Fontes RB, Lotfi CF, Skorupa A, Bartol I, Cipolla-Neto I, Costanzi-Strauss E: Retroviral transfer of the pI6INK4a cDNA inhibits C6 glioma formation in Wistar rats. Cancer Cell Int 2002, 2(I):2.

31. Ferrara N: Vascular endothelial growth factor as a target for anticancer therapy. Oncologist 2004, 9:2-10.

32. Shibuya M: Differential roles of vascular endothelial growth factor receptor- $I$ and receptor-2 in angiogenesis. J Biochem Mol Biol 2006, 39:469-78.

33. Lamszus K, Ulbricht U, Matschke J, Brockmann MA, Fillbrandt R, Westphal M: Levels of soluble vascular endothelial growth factor (VEGF), receptor $I$ in astrocytic tumors and its relation to malignancy, vascularity, and VEGF-A. Clin Cancer Res 2003, 9:1399-405.

34. Das B, Yeger H, Tsuchida R, Torkin R, Gee MF, Thorner PS, Shibuya $M$, Malkin $D$, Baruchel $S$ : A hypoxia-driven vascular endothelial growth factor/FItI autocrine loop interacts with hypoxiainducible factor-lalpha through mitogen-activated protein kinase/extracellular signal-regulated kinase 1/2 pathway in neuroblastoma. Cancer Res 2005, 65:7267-75.

35. Mendes O, Kim HT, Lungu G, Stoica G: MMP2 role in breast cancer brain metastasis development and its regulation by TIMP2 and ERK I/2. Clin Exp Metastasis 2007, 24:34I-5I.

36. Calviello G, Di Nicuolo F, Gragnoli S, Piccioni E, Serini S, Maggiano N, Tringali G, Navarra P, Ranelletti FO, Palozza P: n-3 PUFAs reduce VEGF expression in human colon cancer cells modulating the COX-2/PGE2 induced ERK-I and -2 and HIF-Ialpha induction pathway. Carcinogenesis 2004, 25:2303-10.

37. Maddika S, Ande SR, Panigrahi S, Paranjothy T, Weglarczyk K, Zuse A, Eshraghi M, Manda KD, Wiechec E, Los M: Cell survival, cell death and cell cycle pathways are interconnected: implications for cancer therapy. Drug Resist Updat 2007, 10:13-29.

38. Godefroy N, Lemaire C, Mignotte B, Vayssière JL: p53 and Retinoblastoma protein (pRb):a complex network of interactions. Apoptosis 2006, I I:659-6I.

39. Burkhart DL, Sage J: Cellular mechanisms of tumour suppression by the retinoblastoma gene. Nat Rev Cancer 2008, 8:67I-82.

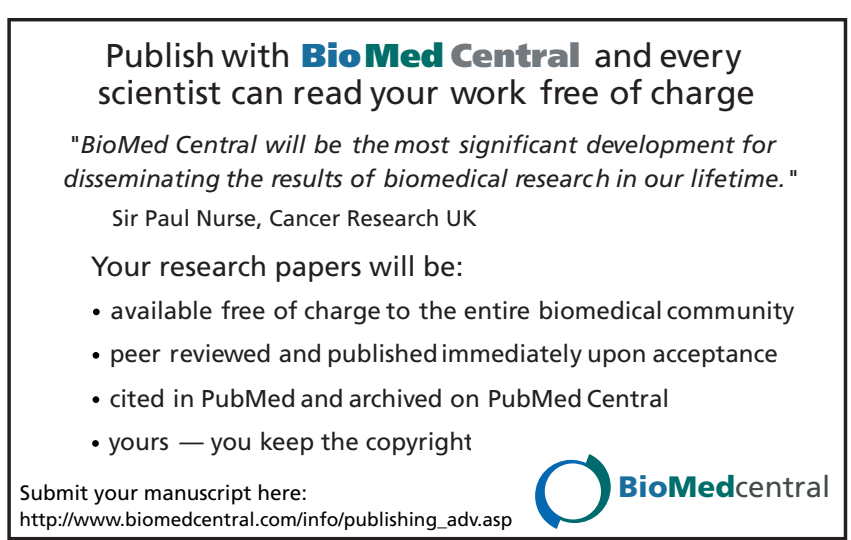

